\title{
A method for the differential determination of plasma antithrombins
}

\author{
V. MUSUMECI, A. VINCENTI, AND B. BIZZI \\ From the Laboratory of Blood Coagulation, Department of Internal Medicine, Catholic University, \\ Rome, Italy
}

SYNOPSIS A method for the differential determination of plasma antithrombins, antithrombin III and $\alpha_{2}$ macroglobulin, is described. The method is based on the selective inactivation of plasma $\alpha_{2}$ macroglobulin by treatment with $0.1 \mathrm{M}$ methylamine for 10 minutes at $37^{\circ} \mathrm{C}$ and on the observation that antithrombin III and $\alpha_{2}$ macroglobulin inhibited in defibrinated plasma low concentrations of thrombin without mutual interference and according to pseudo-first order reaction. In healthy subjects antithrombin III was shown to account for about $70 \%$ of the total antithrombin activity. But in patients with liver cirrhosis, where low levels of total antithrombin activity were observed, the relative contribution of antithrombin III was found to be noticeably lower.

Three different thrombin inhibitors have been purified from human plasma, namely, an $\alpha_{2}$ globulin called antithrombin III (Abildgaard, 1967; Heimburger, 1967), the $\alpha_{2}$ macroglobulin $\left(\alpha_{2} \mathbf{M}\right)$ (Lanchantin et al, 1966; Steinbuch et al, 1968), and the $\alpha_{1}$ antitrypsin (Rimon et al, 1966; Gans and Tan, 1967).

Since thrombin inhibition by $\alpha_{1}$ antitrypsin occurs at thrombin concentrations far above those likely to exist in vivo (Abildgaard, 1969a, b), the antithrombin capacity of plasma appears to be exerted only by antithrombin III and by $\alpha_{2}$ macroglobulin.

The methods available to determine the antithrombin activity of plasma invariably measure the combined inhibition of thrombin by both inhibitors. The antithrombin activity of purified $\alpha_{2} M$ has been shown to disappear after exposure to methylamine (Steinbuch et al, 1968).

In this paper we examine the possible use of methylamine for the selective inactivation of plasma $\alpha_{2} \mathbf{M}$ in order to obtain a method for the differential determination of plasma antithrombins.

\section{Material}

Nine volumes of whole human blood were collected into plastic tubes containing 1 volume of $3.8 \%$

Received for publication 19 June 1975. sodium citrate. Plasma was obtained by centrifugation at $1500 \mathrm{~g}$ for 15 minutes.

Defibrinated plasma (d-plasma) was prepared by incubating 3-5 ml plasma samples in glass tubes at $56^{\circ} \mathrm{C}$ for 3 minutes with intermittent shaking. After cooling, the precipitate was removed by centrifugation at $2000 \mathrm{~g}$ for 15 minutes.

Standard reference d-plasma was prepared from a pool of 10 healthy donors and stored in small aliquots at $-20^{\circ} \mathrm{C}$.

Tris-buffered saline, pH 7.8 (0.15 M NaCl, $0.01 \mathrm{M}$ Tris), was used as diluent throughout.

Human fibrinogen grade L (AB Kabi, Stockholm, Sweden) was dissolved as indicated by the manufacturer and stored in small aliquots at $-20^{\circ} \mathrm{C}$. Before use it was diluted with buffer to $250 \mathrm{mg} / 100$ ml.

Thrombin (Topostasin, Prodotti Roche SpA, Milan, Italy) was dissolved in buffer to $50 \mathrm{NIH}$ units $/ \mathrm{ml}$ and stored in small aliquots at $-20^{\circ} \mathrm{C}$.

Aluminium hydroxide (British Drug Houses, Poole, UK) was suspended in water. The sediment obtained after centrifugation was used for plasma absorption.

Methylamine hydrochloride (Carlo Erba, Italy) was dissolved in buffer at a concentration of $2.5 \mathrm{M}$ and adjusted to $\mathrm{pH} 7 \cdot 8$ with $1 \mathrm{M} \mathrm{NaOH}$.

Immunochemical quantitation of antithrombin III was determined by radial immunodiffusion on $\mathbf{M}$ Partigen Antithrombin III plate provided by the generosity of Behringwerke AG, Marburg-Lahn, Germany. 
Methods

INFLUENCE OF METHYLAMINE ON THE

CLOTTING ASSAY OF THROMBIN

In order to rule out a possible effect of methylamine on the clotting assay adopted for the determination of thrombin, the following experiments were performed.

Thrombin solutions of varying strength (range 10-0.25 NIH units/ml) were prepared either in buffer or in buffer containing increasing concentrations of methylamine (range 0.02-0.25 M).

Thrombin activity was assayed by adding at $37^{\circ} \mathrm{C}$ $0.1 \mathrm{ml}$ aliquots of thrombin dilutions to $0.2 \mathrm{ml}$ aliquots of fibrinogen solution and recording the clotting time. All determinations were performed in duplicate.

INACTIVATION OF $\alpha_{2}$ M ANTITHROMBIN

ACTIVITY BY METHYLAMINE

Plasma samples showing only $\alpha_{2} \mathbf{M}$ antithrombin activity were prepared by treatment with $\mathrm{Al}(\mathrm{OH})_{3}$, which has been shown to be an effective tool to remove antithrombin III (Monkhouse et al, 1955; Abildgaard, 1967).

d-Plasma was added to $\mathrm{Al}(\mathrm{OH})_{3}$ in a $1: 1$ ratio. The mixture was allowed to stand, with intermittent shaking, at $37^{\circ} \mathrm{C}$ for 15 minutes; it was then centrifuged at $3000 \mathrm{~g}$ for 10 minutes. The supernatant was tested for residual antithrombin III by heparin cofactor assay, according to Abildgaard (1967), and by immunoassay.

Only the samples showing negative results were labelled as $\alpha_{2} \quad M$ samples and were subsequently used.

Increasing amounts of methylamine in $0.1 \mathrm{ml}$ aliquots were added to $0.9 \mathrm{ml}$ aliquots of $\alpha_{2} \mathrm{M}$ sample to give a final methylamine concentration of 0.05-0.1-0.2 M. After 5-10 minutes incubation at $37^{\circ} \mathrm{C}$ the mixtures were diluted with buffer in order to bring the methylamine concentration below $0.04 \mathrm{M}$. Their antithrombin activity was tested as follows: $0.1 \mathrm{ml}$ of thrombin $(50 \mathrm{NIH}$ units $/ \mathrm{ml})$ was added to a $0.6 \mathrm{ml}$ sample at $37^{\circ} \mathrm{C}$; after 3 minutes $0.1 \mathrm{ml}$ was removed and residual thrombin was assayed on $\mathbf{0 . 2}$ $\mathrm{ml}$ of fibrinogen. The results were compared with control assays where $0.6 \mathrm{ml}$ of buffer and $0.6 \mathrm{ml}$ of a correspondingly diluted $\alpha_{2} M$ sample were substituted for methylamine-treated samples.

\footnotetext{
EFFECT OF METHYLAMINE ON

ANTITHROMB IN III

Antithrombin III was obtained by elution of the sediment of the $\mathrm{Al}(\mathrm{OH})_{3}$-treated plasma with $0.36 \mathrm{M}$ phosphate buffer, pH 7.8.
}

The eluted solution was treated with $0.25 \mathrm{M}$ 을 methylamine for 10 minutes at $37^{\circ} \mathrm{C}$, and antithrombin activity was assayed as above.

KINETICS OF THROMBIN INHIBITION BY

ANTITHROMBIN III, BY $\alpha_{2}$ MACROGLOBULIN, AND BY BOTH INHIBITORS

Samples containing only antithrombin III (AT III) were obtained by d-plasma treated with $0.1 \mathrm{M}$ methylamine at $37^{\circ} \mathrm{C}$ for 10 minutes.

According to the above experiments this procedures should result in d-plasma samples practically free of $\alpha_{2} M$ activity and containing the original AT IIS concentration.

Samples containing only $\alpha_{2} \mathbf{M}$ antithrombin $\vec{b}$ activity were prepared as described above.

AT III and $\alpha_{2}$ M samples were then diluted with buffer in order to obtain samples containing the same concentration of inhibitor as a 1/5 dilution ow d-plasma. The kinetic analysis of thrombin inhibition was performed as follows: $0.2 \mathrm{ml}$ aliquots of thrombin (50 NIH units $/ \mathrm{ml}$ ) were added at $37^{\circ} \mathrm{C}$ to $1.2 \mathrm{ml}$ aliquots of AT III, $\alpha_{2} \mathrm{M}$, and d-plasma diluted samples; at 1 minute intervals $0.1 \mathrm{ml}$ aliquots were removed from the reaction mixtures, ando residual thrombin was assayed on $0.2 \mathrm{ml}$ of fibrinogen. The initial concentration of thrombin was ob류
tained by substituting buffer for samples.

The results (mean values of three experiments) $\vec{b}$ were expressed by plotting the log of thrombin con 3 centration obtained by the standard clotting curve against the time of incubation.

DIFFERENTIAL DETERMINATION OF PLASMA ANTITHROMBIN

Either $0.1 \mathrm{ml}$ of buffer or $0.1 \mathrm{ml}$ of $1 \mathrm{M}$ methylamines were added to $0.9 \mathrm{ml}$ aliquots of the d-plasma to be tested; after 10 minutes incubation at $37^{\circ} \mathrm{C}$ the samples were diluted by adding $4 \mathrm{ml}$ of buffer; $0.6 \mathrm{mb}$ of each dilution and $0.6 \mathrm{ml}$ of buffer were pipettec. on small test tubes and prewarmed at $37^{\circ} \mathrm{C}$ for 30 minutes; $0.1 \mathrm{ml}$ aliquots of thrombin solution (about $50 \mathrm{NIH}$ units $/ \mathrm{ml}$ ) were added to each tube $\stackrel{\circ}{\circ}$ and the mixtures were immediately mixed. After minutes of incubation $0.1 \mathrm{ml}$ aliquots were removed from the reaction mixtures and assayed for residuab thrombin on $0.2 \mathrm{ml}$ of fibrinogen solution. Thई clotting time sample/clotting time buffer ratios were calculated, and the results were expressed as per-0 centages of antithrombin activity by reference to standard curve. This curve was constructed by assay ing serial dilutions $(1 / 2 \cdot 5-1 / 3 \cdot 75-1 / 5-1 / 10)$ of the standard d-plasma with no methylamine treatment and by assuming as $100 \%$ the $1 / 5$ dilutions. 


\section{Results}

The clotting assay adopted for the determination of thrombin gave on log-log paper a linear relationship between clotting time and thrombin concentration. Figure 1 shows that methylamine up to $0.04 \mathrm{M}$ does not influence the assay. At larger concentrations non-linear and different curves are observed. Clotting times are prolonged and the clots had a translucent appearance, suggesting possible interference at the stage of fibrin polymerization.

Treatment of plasma samples with $0 \cdot 1 \mathrm{M}$ methylamine for 10 minutes at $37^{\circ} \mathrm{C}$ was found to be sufficient to inactivate completely the $\alpha_{2} \mathrm{M}$ antithrombin (fig 2). This treatment did not change the AT III activity of the sample, even if methylamine was used at $0.25 \mathrm{M}$ (not shown in figure).

Kinetic studies (fig 3) show that the rates of thrombin inhibition by AT III (MA-treated dplasma), by $\alpha_{2}$ macroglobulin $\left(\mathrm{Al}(\mathrm{OH})_{3}\right.$-treated $\mathrm{d}$ plasma), and by both inhibitors (d-plasma) follow the rules of a pseudo-first order reaction:

$$
\begin{aligned}
& \frac{t k_{1} A T \amalg I}{2 \cdot 303}=\log \frac{T_{0}}{T_{1}} \\
& \frac{t k_{2} \alpha_{2} M}{2 \cdot 303}=\log \frac{T_{0}}{T_{2}} \\
& \frac{t k_{2} A}{2 \cdot 303}=\log \frac{T_{0}}{T_{2}}
\end{aligned}
$$

where $t$ is the time of incubation; $\mathbf{k}_{1}, \mathbf{k}_{\mathbf{2}}$, and $\mathbf{k}_{\mathbf{a}}$ are the rate constants respectively for AT III, $\alpha_{2} \mathrm{M}$, and A (total antithrombin activity); $T_{0}$ is the initial concentration of thrombin; $T_{1}, T_{2}$, and $T_{2}$ are the residual concentration of thrombin of each reaction.

Moreover, it is possible to show (table I) that the inhibition curve produced by both inhibitors (dplasma) can be obtained by the sum of the curves produced separately by each inhibitor. At each time $\log T_{0} / T_{1}+\log T_{0} / T_{2}$ approximates closely to $\log$ $T_{0} / T_{2}$, or, in another way, $T_{0} / T_{1} \times T_{0} / T_{2}$ approximates to $T_{0} / T_{a}$.

Fig 1 Influence of various concentrations of methylamine on the clotting assay of thrombin.

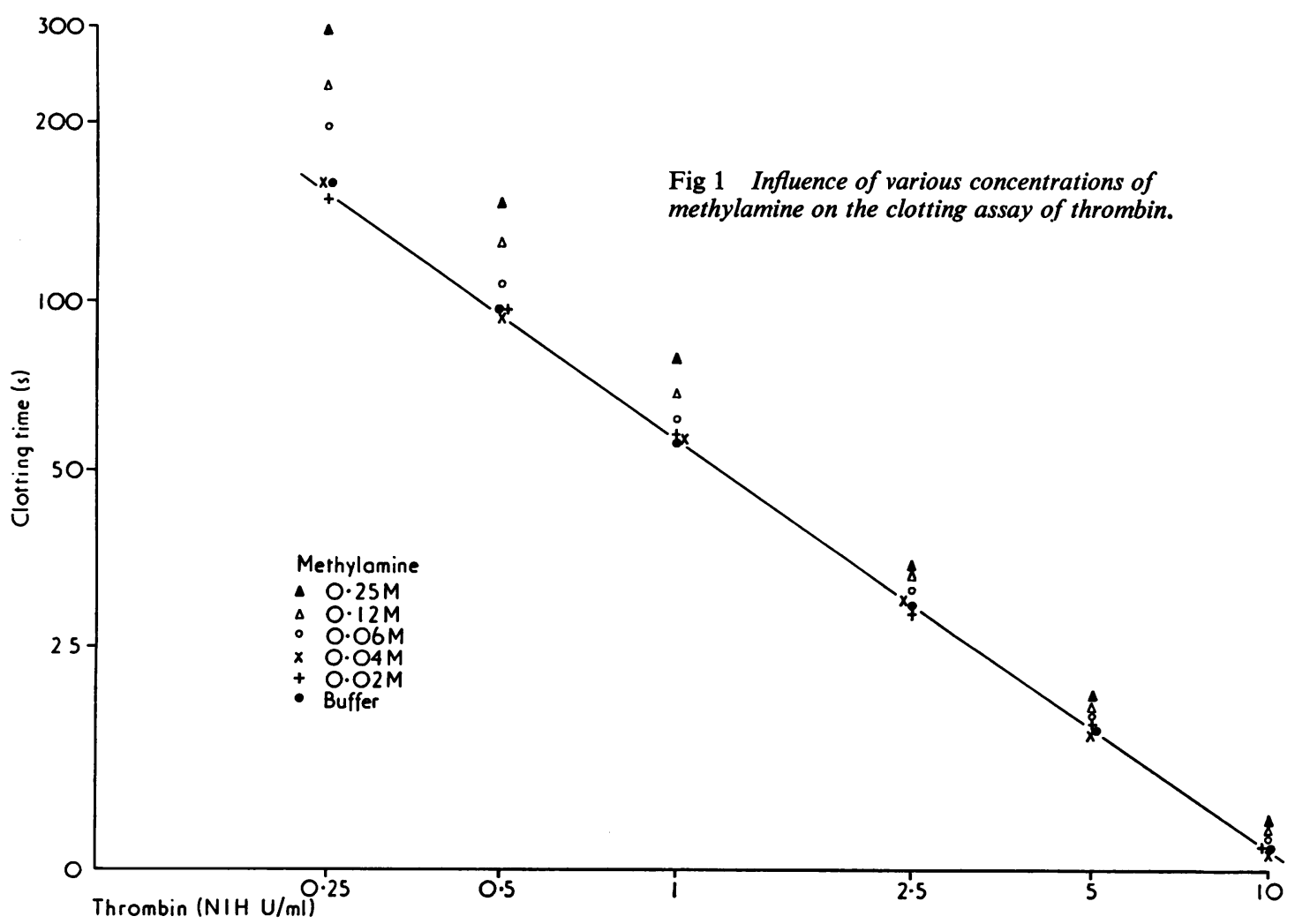




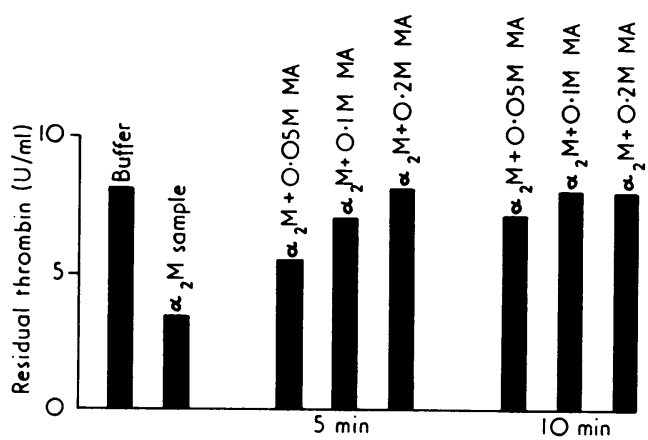

Fig 2 Activity of $\alpha_{2} M$ antithrombin after treatment with various concentrations of methylamine $(M A)$ for 5 to 10 minutes.

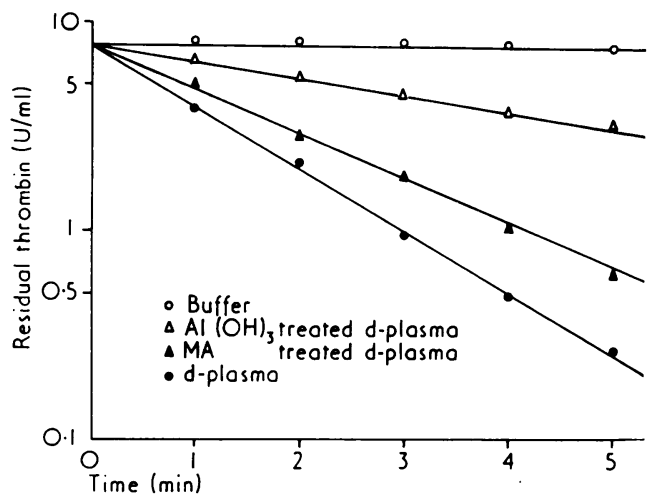

Fig 3 Kinetics of thrombin inhibition by antithrombin III (MA-treated d-plasma), by $\alpha_{2}$ macroglobulin $\left(\mathrm{Al}(\mathrm{OH})_{3}\right.$-treated d-plasma $)$, and by both inhibitors (d-plasma).

These results permit the development of a method for the differential determination of antithrombins.

The antithrombin activity of a sample can be expressed as the rate of thrombin inhibition, for example, as $\log \mathrm{T}_{\mathrm{o}} / \mathrm{T}$ at 3 minutes after the start of the reaction. Since a linear log-log relationship was shown to occur between thrombin concentration and clotting time (fig 1), the expression $\log \mathrm{T}_{\mathrm{o}} / \mathrm{T}$ could well be substituted by $b \log t / t_{o}$, where $t$ and $t_{o}$ are the clotting times corresponding respectively to $T_{0}$ and $\mathrm{T}$, and $\mathrm{b}$ is a constant which could be arbitrarily assumed as 1 when the same fibrinogen batch is used. (The value of $b$ depends on the batch of fibrinogen and was shown to vary in our system between 0.70 and $0 \cdot 88$.)

As expected, a linear relationship was observed on a semi-log representation between inhibition rate of thrombin calculated as $t / t_{o}$ and antithrombin concentration expressed as dilutions of standard dplasma (fig 4).

By assaying simultaneously a sample of d-plasma and a sample of d-plasma treated with methylamine we could obtain respectively the total antithrombin activity and the AT III activity. By subtraction the $\alpha_{2} \mathbf{M}$ antithrombin activity could be calculated.

Results can be expressed as the relative contribution of AT III and $\alpha_{2}$ macroglobulin to the total antithrombin activity, assumed to be 100 .

Results obtained in healthy subjects and in patients with liver cirrhosis are shown in table II. The relative contribution of AT III to the total antithrombin activity, assumed to be 100 , was found to be $72 \cdot 13 \% \pm 5 \cdot 49$ in healthy subjects and $54 \cdot 86 \% \pm$ $9.8 \%$ in patients with liver cirrhosis.

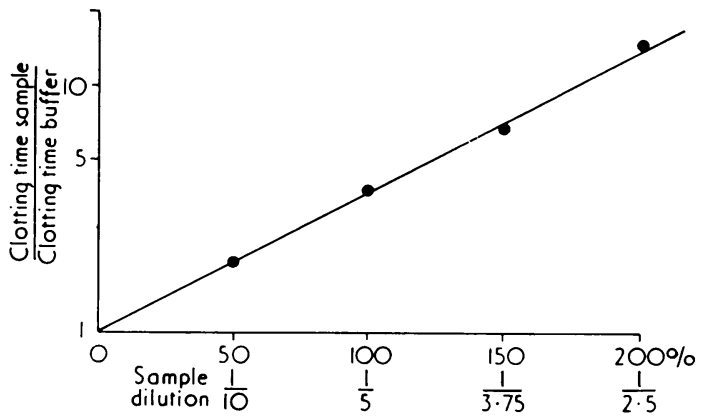

Fig 4 Reference curve for the determination of antithrombin activity as percentage of standard d-plasma.

\begin{tabular}{|c|c|c|c|c|}
\hline \multirow[t]{2}{*}{ Time (min) } & \multirow{2}{*}{$\begin{array}{l}\text { AT III Sample } \\
T_{\mathrm{o}} / T_{1}\end{array}$} & \multirow{2}{*}{$\begin{array}{l}\alpha_{2} M \text { Sample } \\
T_{\mathrm{o}} / T_{2}\end{array}$} & \multicolumn{2}{|l|}{ d-Plasma } \\
\hline & & & $\begin{array}{l}\text { Experimental Value } \\
T_{\mathrm{o}} / T_{\mathrm{a}}\end{array}$ & $\begin{array}{l}\text { Calculated Value } \\
T_{0} / T_{1} \times T_{0} / T_{2}\end{array}$ \\
\hline $\begin{array}{l}1 \\
2 \\
3 \\
4 \\
5\end{array}$ & $\begin{array}{c}1 \cdot 6 \\
2.66 \\
4 \cdot 21 \\
7 \cdot 2 \\
11.9\end{array}$ & $\begin{array}{l}1 \cdot 17 \\
1.42 \\
1.73 \\
2 \cdot 10 \\
2.42\end{array}$ & $\begin{array}{l}2 \\
3 \cdot 72 \\
8 \\
14 \cdot 6 \\
29 \cdot 5\end{array}$ & $\begin{array}{r}1 \cdot 87 \\
3 \cdot 77 \\
7 \cdot 28 \\
15 \cdot 12 \\
28 \cdot 79\end{array}$ \\
\hline
\end{tabular}

Table I Inhibition of thrombin by antithrombin III (AT III sample), by $\alpha_{2}$ macroglobulin ( $x_{2} M$ sample), and by both inhibitors (d-plasma) 


\begin{tabular}{|c|c|c|}
\hline \multirow{2}{*}{$\begin{array}{l}\text { Total Antithrombin Activity } \\
\%(\text { of standard plasma }) \\
\text { Healthy subjects }(n=15)\end{array}$} & Antithrombin III & $a_{2}$ Macroglobulin \\
\hline & \multicolumn{2}{|c|}{ Contribution to the total antithrombin activity assumed to be 100} \\
\hline $103 \pm 15$ & $72 \cdot 13 \% \pm 5 \cdot 49$ & $27 \cdot 87 \% \pm 5.49$ \\
\hline $\begin{array}{l}\text { Patients with liver cirrhosis } \\
60 \\
58 \\
50 \\
70 \\
69 \\
52 \\
47 \\
57 \cdot 86 \% \pm 8 \cdot 84\end{array}$ & $\begin{array}{l}60 \\
53 \\
55 \\
69 \\
62 \\
48 \\
43 \\
54 \cdot 86 \% \pm 9 \cdot 8\end{array}$ & $\begin{array}{l}40 \\
47 \\
45 \\
31 \\
38 \\
58 \\
57 \\
45 \cdot 14 \% \pm 9 \cdot 8\end{array}$ \\
\hline
\end{tabular}

Table II Total and differentiated antithrombin activities in healthy subjects and in patients with liver cirrhosis

\section{Discussion}

According to the law of the pseudo-first order reaction, the method does not require the use of a standardized thrombin solution. The inhibition rate of thrombin by a given antithrombin concentration should not be influenced by minor variations of thrombin concentrations when the antithrombin concentration is in excess with respect to thrombin. Actually it was observed (fig 5) that a 1/5 diluted sample of normal d-plasma produced the same inhibition rate of thrombin when tested with various concentrations of enzyme, ranging from 15 to 60 $\mathrm{NIH}$ units/ml. The irrelevance of a precise thrombin standardization greatly simplifies the antithrombin assay.

Many substances may inhibit the thrombinfibrinogen reaction in human plasma. It is important to make a distinction between antithrombin activity produced by specific substances and a number of aspecific antithrombin reactions which work either by an absorption mechanism (fibrin-antithrombin I), by a kinetic effect (antithrombin IV), or by inter-

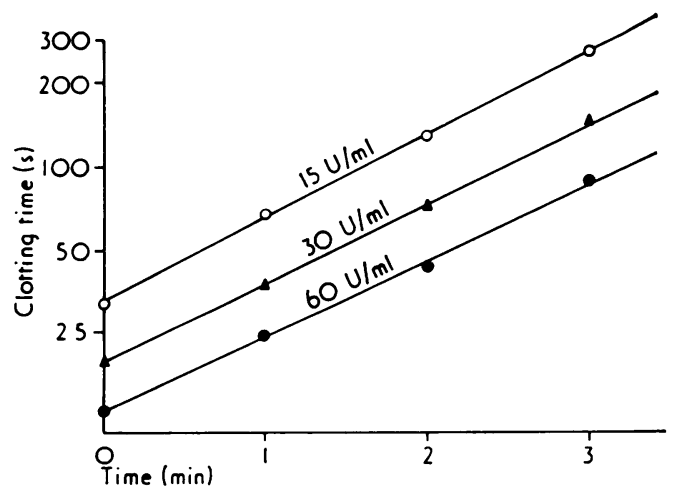

Fig 5 Inhibition rates of various thrombin concentrations produced by a 1/5 diluted sample of d-plasma. ference with the fibrin polymerization (abnormal protein found in hypergammaglobulinaemia or in gamma myeloma-antithrombin V-and fibrin degradation products-antithrombin VI) (Mammen, 1971).

It is rational to use the term antithrombin only for well-characterized substances such as AT III, $\alpha_{2}$ macroglobulin, and $\alpha_{1}$ antitrypsin, which act specifically on thrombin. Two different procedures have been used to determine the antithrombin activity of plasma (Mammen, 1971). The first type of assay reflects the total antithrombin capacity of plasma; it is performed by incubating the plasma with an excess of thrombin and measuring the residual thrombin after completion of the reaction. The other type of assay, which uses small concentrations of thrombin which are likely to occur in vivo, would appear to be more relevant from a physiological and clinical point of view.

The contribution of $\alpha_{1}$ antitrypsin to the total antithrombin activity of plasma seems to be irrelevant when using small concentrations of thrombin. Individuals with congenital $\alpha_{1}$ antitrypsin deficiency showed, with this assay, a normal antithrombin activity (Abildgaard, 1969); moreover, no correlation has been found between immunochemical $\alpha_{1}$ antitrypsin and antithrombin activities (Abildgaard et al, 1970).

The kinetics of thrombin inhibition by AT III and $\alpha_{2}$ macroglobulin appear to be similar; a secondorder reaction was observed with each purified inhibitor in systems containing large concentrations of thrombin (Abildgaard, 1969a, b; Lanchantin et $a l, 1966$; Steinbuch et al, 1968). By using small concentrations of thrombin, pseudo first-order reactions should be expected. This was shown to be the case in our system. In addition, we were able to show that in plasma both inhibitors were acting on thrombin without mutual interference. Our studies showed that the addition of $\mathrm{O} \cdot \mathrm{I} \mathbf{M}$ methylamine to plasma produced in 10 minutes the selective inactivation of $\alpha_{2}$ macroglobulin, the AT III activity remaining unchanged. On the basis of these results we developed 
a method which would permit the differential determination of plasma antithrombins.

Fagerhol and Abildgaard (1970), by removing $\alpha_{2}$ macroglobulin by selective immunoprecipitation, were able to show that AT III accounts for about $70 \%$ of the total antithrombin activity of a plasma sample. These findings were confirmed by our results in healthy subjects, but in patients with liver cirrhosis, in whom a low total antithrombin activity has been found (Hedner and Nilsson, 1973), we found that the relative contribution of AT III may be much lower.

The clinical meaning of this shift in the AT III/ $/ \alpha_{2}$ macroglobulin ratio remains unknown. Antithrombin III is considered to be one of the most important physiological inhibitors of coagulation, acting as a powerful inhibitor of activated factor $\mathbf{X}$ (Biggs et al, 1970) and as heparin cofactor (Rosenberg and Damus, 1973).

An increased tendency to thrombosis has been shown to occur in subjects with congenital AT III deficiency (Kaulla and Kaulla, 1972). Our method could be useful for a sensitive detection of minor changes of AT III concentration as it provides a differential determination of antithrombins.

\section{References}

Abildgaard, U. (1967). Purification of two progressive antithrombins of human plasma. Scand. J. clin. Lab. Invest., 19, 190-195.

Abildgaard, U. (1969a). Studies on the Fibrinogen-fibrin Conversion in Human Plasma. Universitetsforlaget, Oslo.

Abildgaard, U. (1969b). Binding of thrombin to antithrombin III. Scand. J. clin. Lab. Invest., 24, 23-27.

Abildgaard, U., Fagerhol, M. K., and Egeberg, O. (1970). Comparison of progressive antithrombin activity and the concentrations of three thrombin inhibitors in human plasma. Scand. J. clin. Lab. Invest., 26, 349-354.

Biggs, R., Denson, K. W. E., Akman, N., Borrett, R., and Hadden, M. (1970). Antithrombin III, antifactor Xa and heparin. Brit. J. Haemat., 19, 283-305.

Fagerhol, M. K. and Abildgaard, U. (1970). Immunological studies on human antithrombin III: influence of age, sex and use of oral contraceptives on serum concentration. Scand. J. Haemat., 7, 10-17.

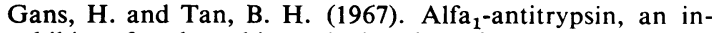
hibitor for thrombin and plasmin. Clin. chim. Acta, 17. 111-117.

Hedner, U. and Nilsson, I. M. (1973). Antithrombin III in a clinical material. Thromb. Res., 3, 631-641.

Heimburger, N. (1967). On the proteinase inhibitor of human plasma with special reference to antithrombin. In First International Symposium on Tissue Factors in the Homeostasis of the Coagulation-Fibrinolysis System, Florence, pp. 353-361.

Kaulla, E. von and Kaulla, K. N. von (1972). Deficiency of antithrombin III activity associated with hereditary thrombosis tendency. J. Med. (Basel), 3, 349-358.

Lanchantin, G. F., Plesset, M. L., Friedmann, J. A., and Hart, D. W. (1966). Dissociation of esterolytic and clotting activities of thrombin by trypsin-binding macroglobulin. Proc. Soc. exp. Biol. (N.Y.), 121, 444-449.

Mammen, E. F. (1971). Determination of antithrombin. In Thrombosis and Bleeding Disorders: Theory and Methods, edited by N. U. Bang, F. K. Beller, and E. F. Mammen, pp. 268-276. Academic Press, New York.

Monkhouse, F. C., France, E. S., and Seegers, W. H. (1955). Studies on the antithrombin and heparin cofactor activities of a fraction absorbed from plasma by aluminium hydroxide. Circulat. Res., 3, 397-408.

Rimon, A., Shamash, Y., and Shapiro, B. (1966). The plasmin inhibitor of human plasma. IV. Its action on plasmin, trypsin, chymotrypsin and thrombin. J. biol. Chem., 241, 5102-5107.

Rosenberg, R. D. and Damus, P. S. (1973). The purification and mechanism of action of human antithrombin-heparin cofactor. J. biol. Chem., 248, 6490-6505.

Steinbuch, M., Blatrix, Ch., and Josso, F. (1968). Action antiprotéase de l'alfa ${ }_{2}$-macroglobuline. II. Sor rôle d'antithrombine progressive. Rev. franç. Etud. clin. Biol., 13, 179-186. 